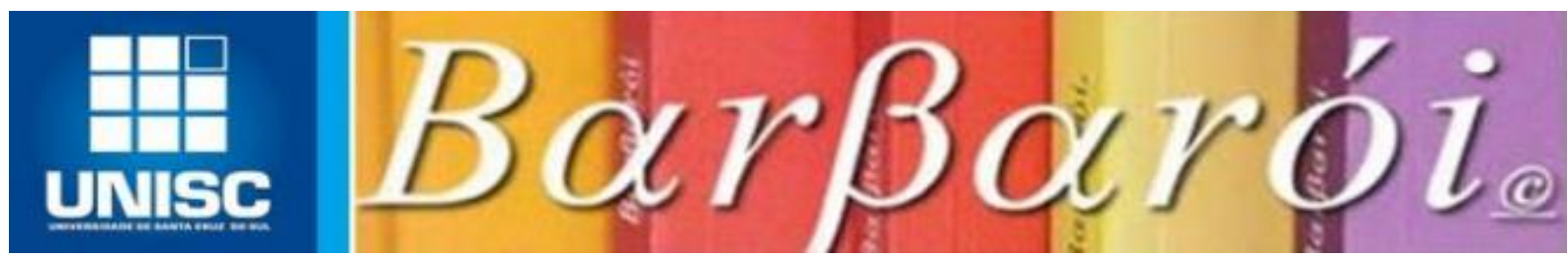

\title{
A CLASSE PESQUEIRA TEM DOIS SEXOS: TRABALHO E RELAÇÕES DE GÊNERO NA CADEIA PRODUTIVA DA PESCA ARTESANAL NA BACIA DE CAMPOS / RJ.
}

\author{
DOI: http://dx.doi.org/10.17058/barbaroi.v51i1.12076 \\ Valdir Júnio dos Santos \\ Universidade Candido Mendes - UCAM - Brasil
}

\section{RESUMO}

Este artigo apresenta os resultados de pesquisa desenvolvidos junto às pescadoras artesanais realizada entre 2015 e 2017 contíguos às comunidades pesqueiras residentes na Bacia de Campos mais vulneráveis aos impactos da exploração do petróleo nas regiões Norte, Noroeste e Lagos do Estado do Rio de Janeiro. O objetivo sedimenta-se na necessidade de se compreender os processos de incorporação da mulher na cadeia produtiva da pesca ao mesmo tempo em que desnudamos os processos sociais (in)visibilizadores no campo da sociabilidade e da divisão social do trabalho. Pretendeu-se a aplicação de uma pesquisa de natureza censitária do tipo Survey e os dados obtidos foram analisados por meio do SPSS, como ferramenta estatística para a obtenção das informações desejadas.

Palavras-Chave: trabalho, relações de gênero e pescadoras.

\section{1- INTRODUÇÃO}

Nesse artigo, partirmos de dois campos analíticos que se complementam de modo orgânico (a divisão sexual do trabalho e as relações de gênero) e objetivamos problematizar as fronteiras que estão circunscritas a espaços (in)visibilizadores, que ganham consubstancialidade ao analisarmos as comunidades pesqueiras. Ao direcionarmos as análises para o universo do trabalho, temos como elemento central as diferenças e as especificações de gênero, por acreditarmos que essa metodologia analítica permite ao pesquisador observar a heterogeneidade das experiências e detectar o movimento de constituição dos sujeitos, sobrepujando as transformações por que passaram e como constituíram suas práticas cotidianas.

A pesquisa concentra-se na atuação da mulher pescadora como sujeito ativo, de modo que os estereótipos e os confinamentos espaciais de suas atividades produtivas possam ser questionados e problematizados. Temos como recorte espacial os sete municípios 
contemplados pelo Projeto Pescarte $^{1}$ (São Francisco de Itabapoana, São João da Barra, Campos dos Goytacazes, Quissamã, Macaé, Cabo Frio e Arraial do Cabo) num total de 38 comunidades e 247 localidades $^{2}$. Os dados analisados neste artigo foram retirados do mapeamento das famílias da pesca (Censo Pescarte), que entrevistou 3.478 famílias as quais totalizam 10.082 pessoas $(55,2 \%$ de homens e $44,8 \%$ mulheres $)$ destas, foram identificadas 4.234 pessoas ligadas diretamente à pesca artesanal (72,3\% homens e 27,7\% mulheres).

Os resultados obtidos oferecem algumas pistas sobre a inserção da mulher na cadeia produtiva da pesca centralizada em três eixos analíticos fundamentais: 1- a organização; 2 - o planejamento; e a 3 - gestão. Por organização entende-se a necessidade de captura dos códigos sociais em que homens e mulheres conjugam seu real vivido, indicando a importância de se analisar o cotidiano da pesca artesanal e os espaços ocupados por essas mulheres nas principais formas de organizações sociais - grupos, associações, cooperativas, sindicatos e federação. A análise do planejamento nos dará elementos para se pensar as principais contradições que se interpõem no mundo da pesca artesanal, e a sensibilidade do pesquisador irá direcioná-lo para a descrição densa das práticas e dos discursos associados aos significados socioculturais coletivos de gênero e trabalho. O conceito de gestão fecha o triângulo metodológico. Esse conceito sumariza as formas pelas quais a organização e o planejamento se replicam e se interpenetram na representação de um regime simbólico misto que rege tal relação de gênero no âmbito da pesca artesanal.

Mapa 1 - Abrangência Territorial do Projeto Pescarte. 


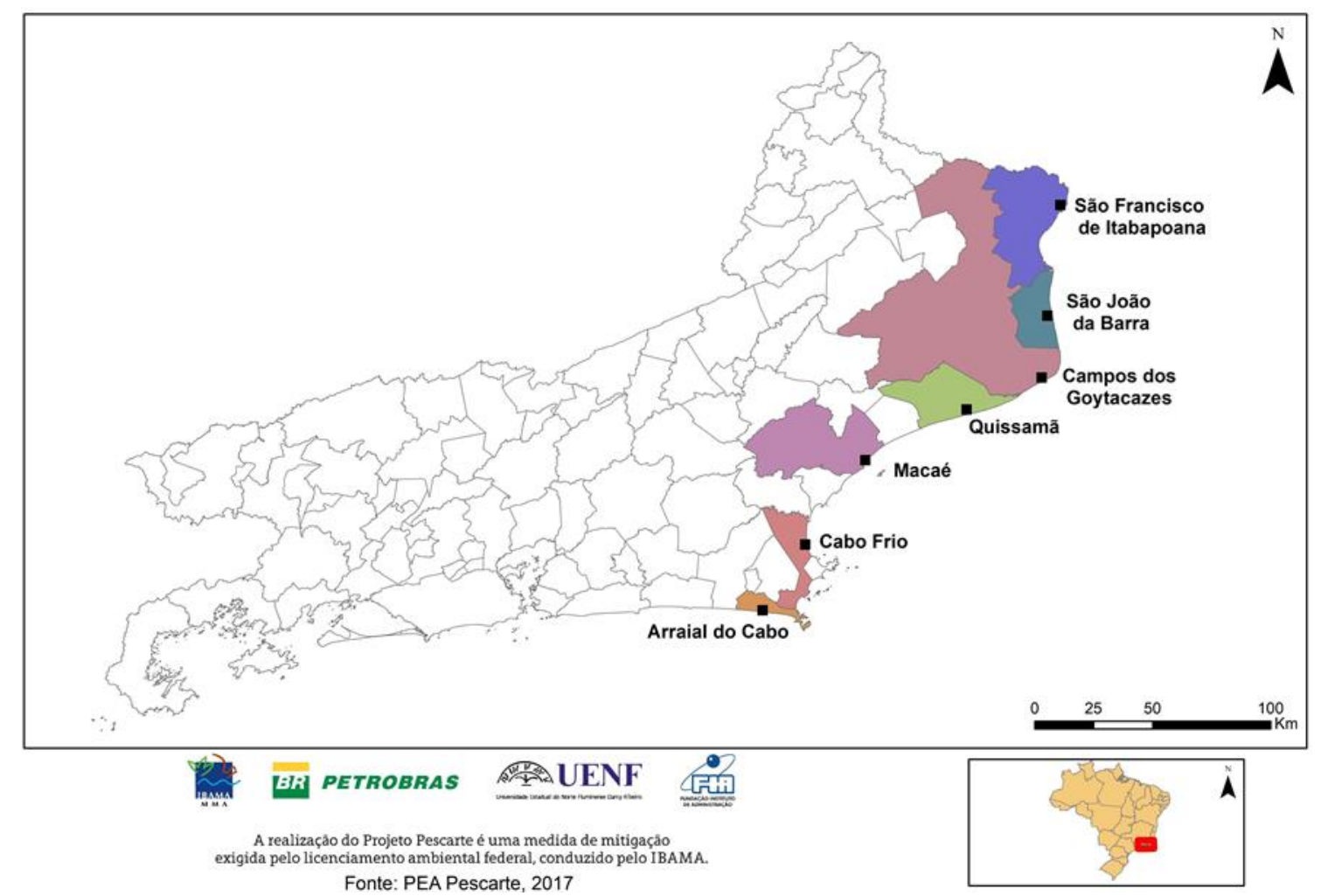

O fato é que as mulheres pescadoras configuram-se como o grupo mais vulnerável (vivenciam a precarização, tanto em relação a salários, direitos e condições de trabalho), em que os dualismos abstratos indicam a necessidade de incorporação da unidade familiar ${ }^{3}$ como meio de emancipação social das pescadoras. É importante destacar que as mesmas apresentam níveis de polivalência e multiatividades importantes para o principio da organização social. Dessa forma, o presente artigo visa demostrar ao leitor os diferentes estágios de vivências da pesca experienciados pelas mulheres pescadoras, em que o fazer científico estrutura-se em meio ao debate da "Slow Science", constituindo um diálogo denso e profundo, partindo do saber construído no cotidiano praticado.

\section{2 - TRABALHO E GÊNERO: identidade profissional e sexismo.}

Em meio aos desígnios da sociedade moderna, os sujeitos sociais passaram a contrapor o elemento natureza como fonte de sua essência e a encará-la de modo predatório irrompendo sua ontologia. Esse sujeito social que transforma a natureza - via trabalho - e é transformado carrega em si o potencial de alterar o meio em que vive e a desenvolver suas atividades. Esse 
potencial dinamiza o processo de racionalização que enriquece não só sua atividade como o desenvolvimento laborativo e as suas novas necessidades, favorecendo a:

Criação do sujeito social com ricas e múltiplas faculdades, com sentimentos profundos, dotado de curiosidade científica, aspirações religiosas, estéticas, do conhecimento e do conhecimento prático cotidiano. O trabalho [...] objetivação de forças essenciais humanas [...] cria, pois, a possibilidade permanente de evolução humana: a própria história (IAMAMOTO, 2011, p. 42).

É nesse contexto ontológico do ser social - em que a construção da história expõe a complexidade das realidades vividas e sentidas no cotidiano - que não podemos negar a história dos lugares e a necessidade epistemológica do sentir essas diferenças como elementos estruturantes da cultura e dos códigos sociais. Os pescadores e pescadoras, nesse sentido, são sujeitos sociais dotados de um fazer e ler a natureza que dão materialidade às suas condições concretas de trabalho e às relações de gênero em seu meio constituído (SILVA, 2014).

Essa leitura nos permite reconhecer que esses sujeitos sociais fazem parte da territorialidade natural e que qualquer aproximação político-cientifica deve estar sensível a essa relação pescador/pescadora/natureza/trabalho e a construção de suas heranças culturais. Esses elementos criam um novo paradigma epistemológico que "requer que se supere a limitação de ver os pescadores artesanais como objeto estáticos e como incapazes de pensar sobre sua própria condição social e histórica” (SILVA, 2014, p. 17).

Portanto, é importante pensar a pesca e as relações de gênero tanto em meio à sua especificidade constitutiva como articulada a um projeto de sociedade que define formas diferenciadas de inserção social combinada a uma identificação cultural, que definem atividades e papéis aos diferentes sexos (ABRAMOVAY \& SILVA, 2000). No contexto mais amplo, podemos delinear que a identidade feminina sempre esteve enquadrada nos padrões da estrutura social do patriarcado, que dominam o modo de ser/sentir e agir conforme seus desígnios. Dessa forma, ao gênero feminino, é ensinado ser filhas, mães, donas-de-casa e a aceitar seu papel de subordinação. O padrão de divisão sexual do trabalho tem seus reflexos no mercado de trabalho, no momento em que criam nichos produtivos voltados para as mulheres, associado ao cuidado e aos homens profissões que se destacam as características tidas como masculinas (valorizando a força, a destreza, a resistência e a liderança). Dentro desse modelo de família patriarcal, restou à mulher o ambiente privado, cabendo-lhe as responsabilidades domésticas e socializadoras e uma identidade profissional muitas vezes 
articulada ao mundo doméstico. A situação diferencial entre homens e mulheres no mercado de trabalho:

[...] parece ser justificada pela ideia de que o trabalho da mulher é algo secundário [...] a ideia de trabalho secundário é estruturada pela imagem de uma família nuclear, com a mulher como principal/exclusiva responsável pelo cuidado doméstico, e o homem como principal/exclusivo provedor da família. Dessa forma, o acesso e melhores condições de trabalho é algo priorizado ao homem na sociedade [...] (CHIES, 2010, p.514).

No contexto das comunidades pesqueiras, esse quadro não é muito diferente. O trabalho das pescadoras, mesmo sendo, na maioria dos casos, interpretado como secundário, tem uma importância estratégica para toda a unidade familiar. As mulheres costumam articular em seu cotidiano várias atividades produtivas e reprodutivas. Em meio a esse contexto os dados coletados demostram que as principais atividades produtivas direcionadas a população feminina são: pesca e coleta de mariscos; venda e processamento do pescado; diversificação das fontes de rendas familiares (a pluriatividade) na agricultura, no artesanato, no comércio e nos serviços. A mulher também ajuda na tecelagem e remendo das redes de pesca, preparo de linhas e iscas. Em alguns casos, foi possível identificar mulheres como membros de tripulação, fato este demarcado pela atividade em família geralmente, a mulher era esposa do proprietário do barco, sendo esta uma estratégia de compensação para os rendimentos declinantes com despesas e acordos de partilhas.

Os dados do Censo Pescarte nos revelam que as pescadoras também têm suas vidas profissionais articuladas à sua dupla função produtiva e reprodutiva. As pescadoras são as principais responsáveis pela reprodução social do grupo familiar, o que implica obrigação com as atividades domésticas, saúde e educação dos filhos. Na mulher, mesmo tendo ajuda (em sua maioria vinda das filhas mais velhas), persistem a responsabilidade pelos cuidados e o seu protagonismo nas decisões intrafamiliar no que diz respeito à educação dos seus descendentes diretos $(56,7 \%)$, compras diárias $(48,8 \%)$ e controle das atividades dos filhos $(60,4 \%)$. Ao observarmos a Tabela 2 , podemos analisar que a atividade que requer um maior controle financeiro tem uma maior participação decisória de ambos, homens e mulheres, como as compras de bens de maior valor $(44,3 \%)$ e as decisões relacionadas ao lazer familiar $(50,8 \%)$.

Tabela 1- Ajuda na Organização de Tarefas.

$$
\text { TAREFAS }
$$




\begin{tabular}{|l|l|l|}
\hline Do lar & $59,5 \%$ & $40,5 \%$ \\
\hline Cuidado com as crianças & $52,6 \%$ & $47,4 \%$ \\
\hline Cuidado com os doentes & $46,2 \%$ & $53,8 \%$ \\
\hline Limpeza do domicílio & $61,4 \%$ & $38,6 \%$ \\
\hline Pequenos reparos & $38,2 \%$ & $61,8 \%$ \\
\hline
\end{tabular}

Fonte: Censo Pescarte.

Tabela 2 - Tomada de Decisão.

\begin{tabular}{|l|c|c|c|c|}
\hline & MULHER & HOMEM & AMBOS & OUTROS \\
\hline Escola dos filhos & $56,7 \%$ & $3,6 \%$ & $36,7 \%$ & $3,0 \%$ \\
\hline Compras diárias & $48,8 \%$ & $14,8 \%$ & $34,3 \%$ & $2,1 \%$ \\
\hline $\begin{array}{l}\text { Horários das atividades dos filhos } \\
\text { (estudar, brincar, dormir, etc.) }\end{array}$ & $60,4 \%$ & $4,7 \%$ & $32,0 \%$ & $2,8 \%$ \\
\hline Compras de bens de maior valor & $42,7 \%$ & $12,0 \%$ & $44,3 \%$ & $0,8 \%$ \\
\hline Passeio / lazer da família & $34,9 \%$ & $10,6 \%$ & $50,8 \%$ & $3,8 \%$ \\
\hline
\end{tabular}

Fonte: Censo Pescarte.

O fato é que os encargos das mulheres sobre o cuidado acabam sendo os grandes modeladores de sua inserção no mercado de trabalho, ou seja, suas atividades produtivas estão sempre sendo reguladas por suas atividades reprodutivas. Portanto, a falta de equipamentos coletivos públicos acaba aumentando os custos da maternidade e do cuidado com o lar. Mas, ao mesmo tempo, fortalece as redes de solidariedade local, como a ajuda de vizinhos e de parentes mais próximos.

O trabalho produtivo da mulher, na maioria dos casos, é subestimado, principalmente por estar associado, com frequência, a uma atividade estritamente doméstica. No caso das pescadoras, muitas de suas atividades produtivas são reconhecidas como atividade reprodutiva (por ocorrer no espaço da casa, como a filetagem, a limpa, o descasque de camarão etc.). Esse quadro dificulta o processo de autoreconhecimento de uma identidade profissional, cujos danos se dão tanto no âmbito cultural como na ausência de políticas públicas específicas. Portanto, é fundamental problematizar a identidade profissional e seu construto em meio social tradicional, como a pesca artesanal.

Dessa forma, precisamos entender a identidade profissional como elemento situacional dependente dos contextos históricos e dos diferentes segmentos da população. Essa construção analítica dialoga com o princípio de que a identidade profissional carrega em si um dinamismo importante para se pensar a construção social de uma profissão e os elementos que constituem a luta pelo reconhecimento. A delimitação da identidade profissional das pescadoras perpassa pela problematização da naturalização dos processos sociais, que determinam nichos femininos fortemente marcados por estereótipos, que polarizam e se 
territorializam em uma visão bipolarizada ("o mar de dentro" para as mulheres e "o mar de fora” para os homens) do ordenamento espacial de divisão simbólica das atividades. A identidade profissional das pescadoras está carregada pelo entendimento vicioso alinhado ao julgamento de capacidades - que estão "com frequência entrelaçado com a avaliação de uma identidade social" da mulher que "são irrelevantes à competência profissional" da mesma (SCOTT, 2005, p.71).

Esses encarceramentos laborativos femininos refletem a uma angústia social de intervenção nos moldes socialmente aceitos da estrutura social, ou seja, existe o temor que os pilares da dominação de gênero incorporem as transformações nos papéis sociais desenvolvidos por homens e mulheres, tendo como desdobramento a reestruturação das relações sociais no âmbito familiar, na economia, no mercado de trabalho e na politica. Portanto, o movimento natural e inicial é de repulsão desses processos em meio social tradicional na tentativa de manter a ordem instituída (SORJ, 2004).

Nesse contexto, identificamos ao longo do trabalho de campo a existência de uma pluralidade semântica no que diz respeito à identidade profissional atribuída às mulheres inseridas na cadeia produtiva da pesca e que denotam uma segregação ocupacional: pescadoras; trabalhadoras da pesca; isqueiras; camaroeiras; marisqueiras; caranguejeiras; evisceradeiras; desfiladeiras; descascadeiras; descascadeiras de siri; descabeçadeiras; redeiras; catadeiras de algas marinhas; e aquicultoras. Essa pluralidade parece parcelarizar a classe e dificulta a construção de identidade profissional reconhecida pelo Estado e pelas políticas públicas. Foi possível perceber que a utilização do termo "Pescadora" é um ponto de mobilização que ultrapassa a demarcação do padrão masculino da pesca e amplifica para uma categoria de luta que incorpora os campos de direitos específicos, como os previdenciários, as questões de cidadania e o reconhecimento como elo importante na cadeia produtiva da pesca frente às instituições de representação de classe. Esse movimento torna-se importante, no que circunscreve ao tema central, a todo um ergástulo de problemas que dificulta o reconhecimento social e político dessas mulheres frente a direitos sociais e ao próprio reconhecimento de seus pares como pescadoras.

Ao analisar o comportamento da força de trabalho feminina, no que diz respeito ao reconhecimento dos nichos de trabalho feminino na pesca artesanal na Bacia de Campos, os dados do Censo Pescarte revelam que 70,6\% das mulheres entrevistadas não reconhecem o 
exclusivismo de atividades coadunadas ao sexo, ou seja, não existem espaços laborais exclusivos para homens, no qual mulher não pode ou não deve participar. Contrariando essa visão, 29,4\% reconhecem a bipolaridade laboral e a existência de postos de trabalho exclusivos para homens em que mulheres, por uma questão cultural, não deveriam participar. As mulheres que reconhecem a divisão laboral entre os gêneros indicaram a pesca como a principal atividade masculina $(76,9 \%)$, e os nichos femininos, ligados à filetagem $(13,1 \%)$, ao descasque $(12,2 \%)$, à limpeza $(9,2 \%)$ e à pesca, que aparece com $2,6 \%$ das respostas.

Tabela 3 - Atividades exclusivas para Homens na Pesca Artesanal.

\begin{tabular}{|l|c|}
\hline \multicolumn{1}{|c|}{ Atividades } & $\begin{array}{c}\text { Porcentage } \\
\text { m (\%) }\end{array}$ \\
\hline Pesca & $76,90 \%$ \\
\hline Pesca/Transporte & $4,20 \%$ \\
\hline Pesca/Comercialização/Negociação/Transporte & $3,80 \%$ \\
\hline Pesca/Comercialização/Negociação & $2,90 \%$ \\
\hline Todas as opções listadas & $1,70 \%$ \\
\hline Pesca, Comercialização/Negociação/Transporte/Beneficiamento/Venda & $0,80 \%$ \\
\hline $\begin{array}{l}\text { Pesca/Comercialização/Transporte/Beneficiamento/Descasque/Evisceração/Filetagem/Cata/Limpeza/V } \\
\text { enda }\end{array}$ & $0,80 \%$ \\
\hline Comercialização/Negociação & $0,80 \%$ \\
\hline Pesca/Venda & $0,40 \%$ \\
\hline
\end{tabular}

Fonte: Censo Pescarte.

Tabela 4 - Atividades Exclusivas para Mulheres na Pesca Artesanal.

\begin{tabular}{|l|c|}
\hline \multicolumn{1}{|c|}{ Atividades } & Porcentagem (\%) \\
\hline Filetagem & $13,10 \%$ \\
\hline Descasque & $12,20 \%$ \\
\hline Limpeza & $9,20 \%$ \\
\hline Descasque/Filetagem/Limpeza & $8,30 \%$ \\
\hline Filetagem e Limpeza & $3,90 \%$ \\
\hline Descasque e Limpeza & $3,50 \%$ \\
\hline Beneficiamento/Descasque/Filetagem/Limpeza & $3,10 \%$ \\
\hline Cata/Extração de Mariscos & $3,10 \%$ \\
\hline Pesca & $2,60 \%$ \\
\hline
\end{tabular}

Fonte: Censo Pescarte.

Os dados nos revelam que a premissa das relações sociais de gênero cria padrões de participação feminina e desnuda o fato de que os fatores limitadores ainda continuam fortes no cenário pesqueiro. Os padrões culturais e sociais ainda sustentam modelos de comportamentos e valores, cujos reflexos são sentidos nos campos estruturais, legais e ideológicos, dificultando o acesso de mulheres pescadoras às políticas públicas, que carregam potencialidade de solidificação do processo de emancipação, ou seja, a questão do empoderamento é importante na quebra das estruturas de dominação e desigualdade de gênero. Mas também não podemos deixar de delinear a ocorrência de mudanças (visto os 
dados acima), sendo possível identificar um lento, porém significativo processo de alteração, visto a importância e o peso do trabalho feminino para o fortalecimento da organização social e de novos processos de emancipação social da classe pesqueira dos municípios da Bacia de Campos.

Como elemento de permanência, os homens continuam sendo os principais provedores do sustento familiar, como indicaram $56,9 \%$ das respondentes, seguido por ambos $(23,6 \%)$; a mulher aparece com $13,2 \%$.

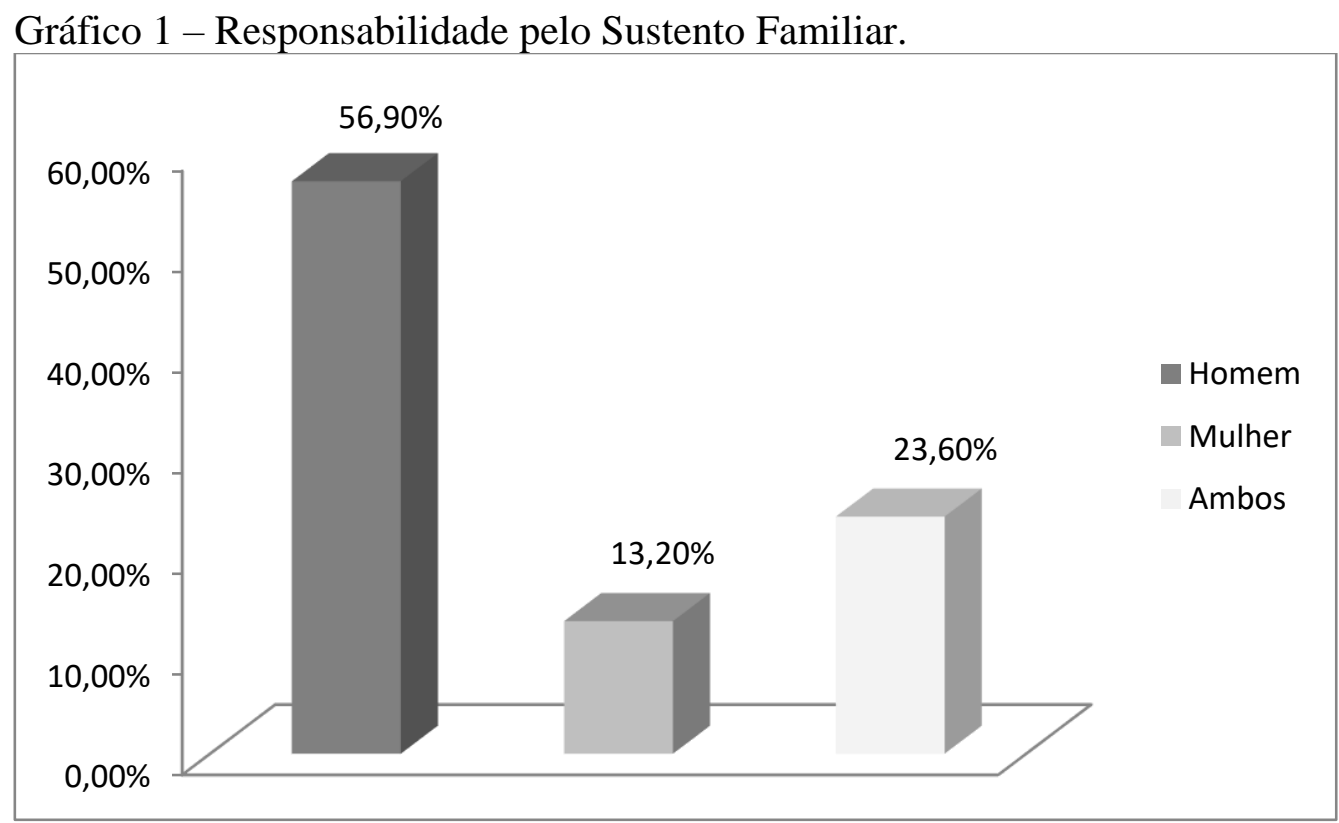

Fonte: Censo Pescarte.

As mudanças se confirmam quando analisamos os dados do censo Pescarte no que diz respeito à importância da renda advinda do trabalho da mulher. A crescente participação econômica feminina tem ajudado a assegurar a situação de bem-estar familiar e a defender o seu nível socioeconômico. Os dados mostram que a renda advinda do trabalho feminino contribui para metade do orçamento familiar (24,9\%), assiste com metade (17,9\%), auxilia com pouco $(17,3 \%)$ e participa com mais da metade $(10 \%)$. O fato é que, se levarmos em conta os diferentes níveis de contribuições, sejam elas poucas ou muitas, o trabalho feminino está colaborando com aproximadamente $70,1 \%$ do orçamento familiar. Mas também é importante destacar que, para 8,7\% das respondentes, o trabalho feminino é a única fonte de renda, contrapondo-se a $21,2 \%$ das respondentes, que indicaram que seu trabalho contribui em nada para o orçamento familiar.

Gráfico 2 - Contribuição do Trabalho Feminino para o Orçamento Familiar. 


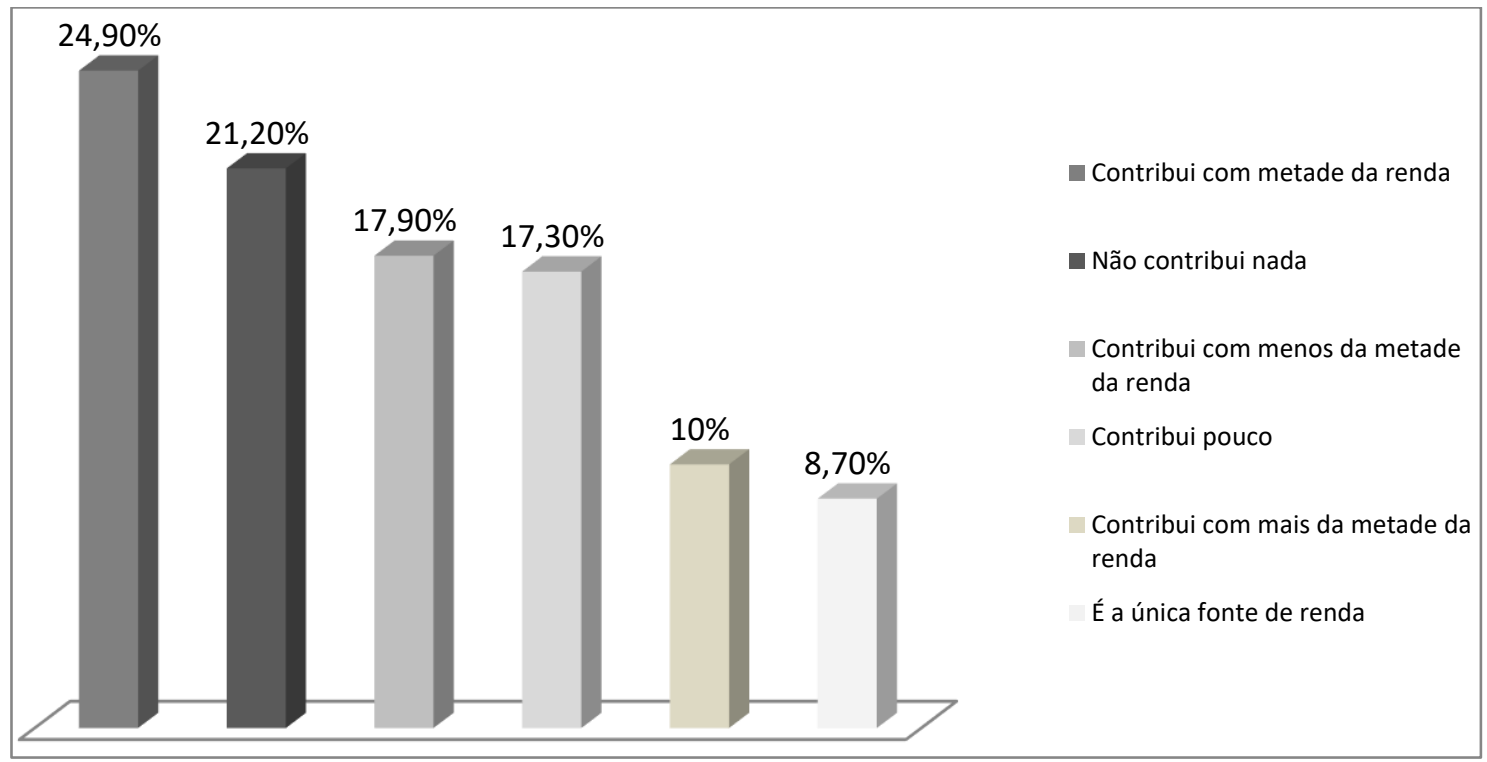

Fonte: Censo Pescarte.

Esses dados são importantes para compor o quadro do comportamento da força de trabalho feminina na pesca artesanal e para chamar atenção da importância de se solidificar os movimentos, mesmo que tímidos, de empoderamento, articulados à participação e aos novos olhares e novos conteúdos do trabalho feminino, questionando relações e ideologias. Portanto, essas novas perspectivas são dinamizadores dos elementos que compõem a organização social e a importância da incorporação das pescadoras, não como elemento de figuração, mas como elo importante na luta política por novos patamares de emancipação.

\section{3 - Representação e Participação Social das Pescadoras:}

A intensificação da presença feminina em novos nichos do mercado de trabalho vem contribuindo para alterar o perfil e as práticas das organizações de classe. É em meio a esse contexto que o Projeto Pescarte vem ampliando os espaços de atuação das mulheres e fortalecendo as lideranças femininas, de modo a avigorar sua participação nas instâncias decisórias do projeto, intensificando as atividades de mobilização das pescadoras em torno de suas demandas por meio do engajamento das mesmas nos Grupos Gestores ${ }^{4}$. A estratégia do projeto foi assegurar em todos os municípios a reserva de vagas para mulheres e para representantes da pesca de interiores e continentais. Analisando os dados do quantitativo dos 
eleitos, é possível perceber que as mulheres representam aproximadamente $36 \%$ do quantitativo total eleito pelos grupos gestores.

Tabela 5 - Composição de Gênero nos Grupos Gestores.

\begin{tabular}{|l|c|c|}
\hline \multicolumn{3}{|c|}{ Composição dos Grupos Gestores } \\
\hline Municípios & Homens & Mulheres \\
\hline Campos dos Goytacazes & 11 & 15 \\
\hline Cabo Frio & 20 & 6 \\
\hline Arraial do Cabo & 16 & 9 \\
\hline São João da Barra & 18 & 6 \\
\hline São Francisco de Itabapoana & 15 & 7 \\
\hline Quissamã & 9 & 8 \\
\hline Macaé & 8 & 3 \\
\hline Total & 97 & 54 \\
\hline
\end{tabular}

Fonte: Censo Pescarte.

A importância de se assegurar a participação feminina nos espaços associativos advém da baixa participação feminina nos movimentos de organização de classe, que, na maioria dos casos, são explicados por sua condição de outsiders, dada pela desigualdade de sua representação e de sua capacidade de influenciar a tomada de decisão (Araújo; Ferreira, 2000). Os dados do Censo Pescarte confirmam essa análise ao demostrar que $55 \%$ das pescadoras não participam de instituições associativas e que $45 \%$ participam dessas instituições.

Gráfico 3 - Participação Feminina em Instituições Associativas.

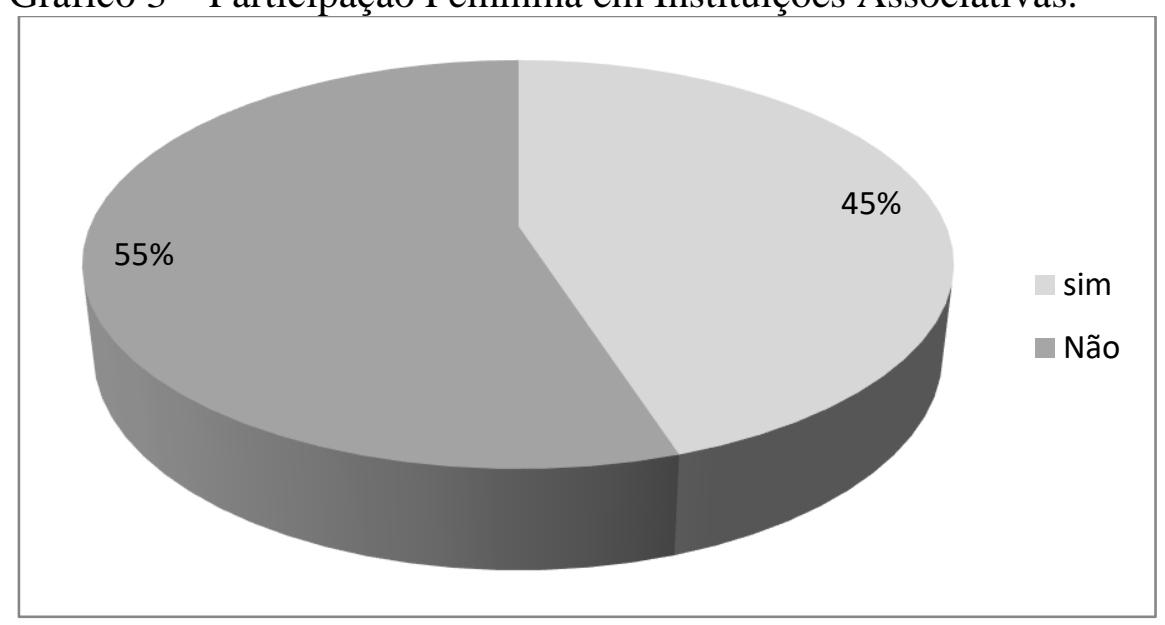

Fonte: Censo Pescarte.

A colônia de pescadores $(74,4 \%)$ representa a principal referência de instituição associativa entre as mulheres pescadoras que participam de organização política de classe. A 
colônia ganha destaque por ser a instituição de luta e reivindicação mais próxima e mais presente para as pescadoras.

Gráfico 4 - Participação das Pescadoras em Instituições Associativas.

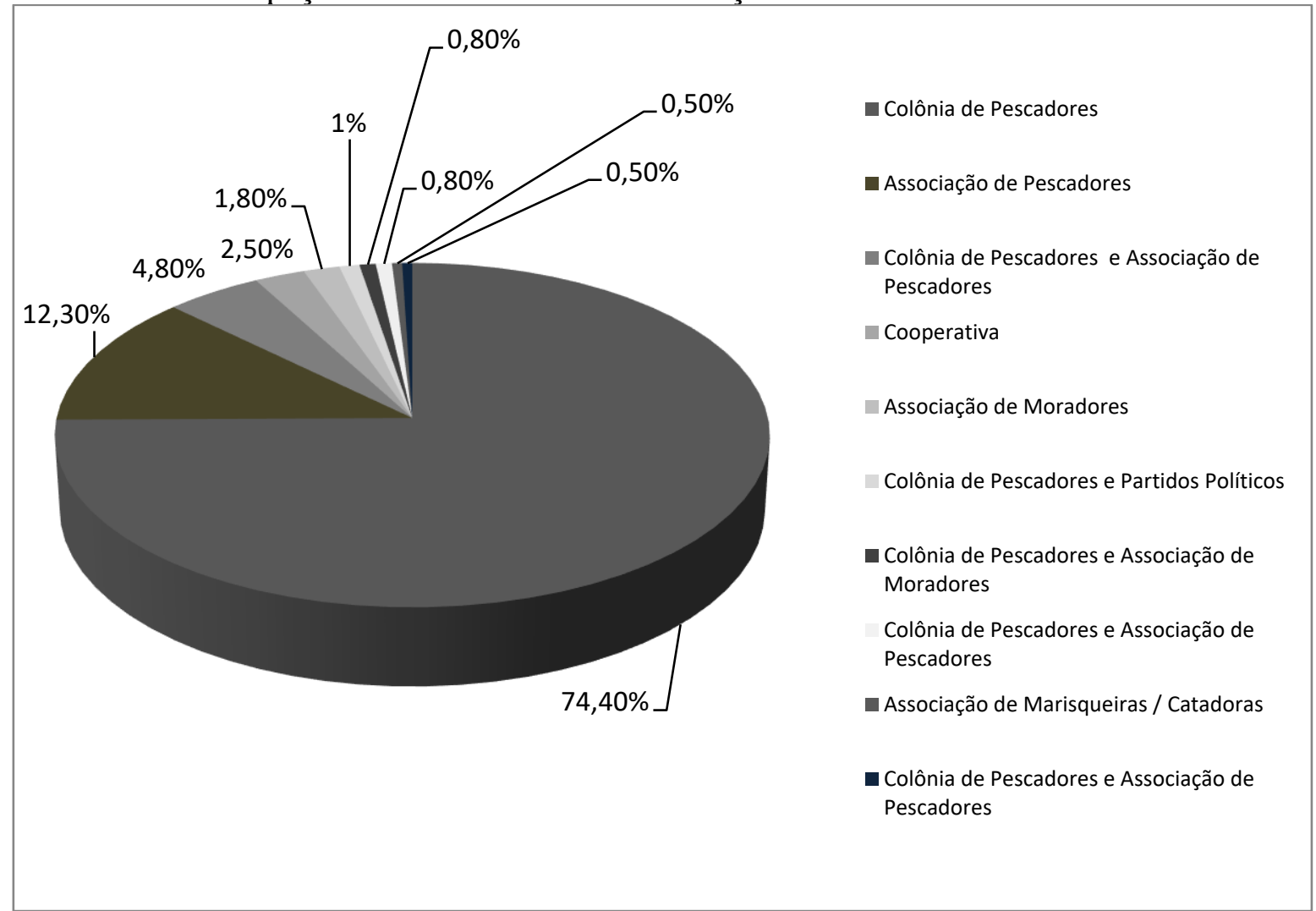

Fonte: Censo Pescarte.

A possibilidade de uma militância mais ativa das mulheres esbarra em vários obstáculos, principalmente o não reconhecimento das especificidades produtivas e vivência das pescadoras por parte das lideranças sindicais. O fato é que a imagem e a ação das instituições associativas percebem a luta feminina como complementar à luta do homem, fazendo com que a organização dessas instituições se estruture "em função do cotidiano dos homens desconsiderando as responsabilidades domésticas das mulheres" (ARAÚJO; FERREIRA, 2000, p. 312). Quando qualificamos a participação nas decisões pelas pescadoras participantes de instituições associativas, os dados revelam que 84,5\% das respondentes indicam que participam apenas como ouvintes, não intervindo nas decisões tomadas, principalmente pelos homens, e apenas $14,9 \%$ indicam participar diretamente das decisões, incutindo pautas e reivindicações femininas vislumbrando uma mudança de paradigma no sentido de transformar esses espaços também em um espaço coletivo de lutas das pautas femininas na pesca artesanal. 


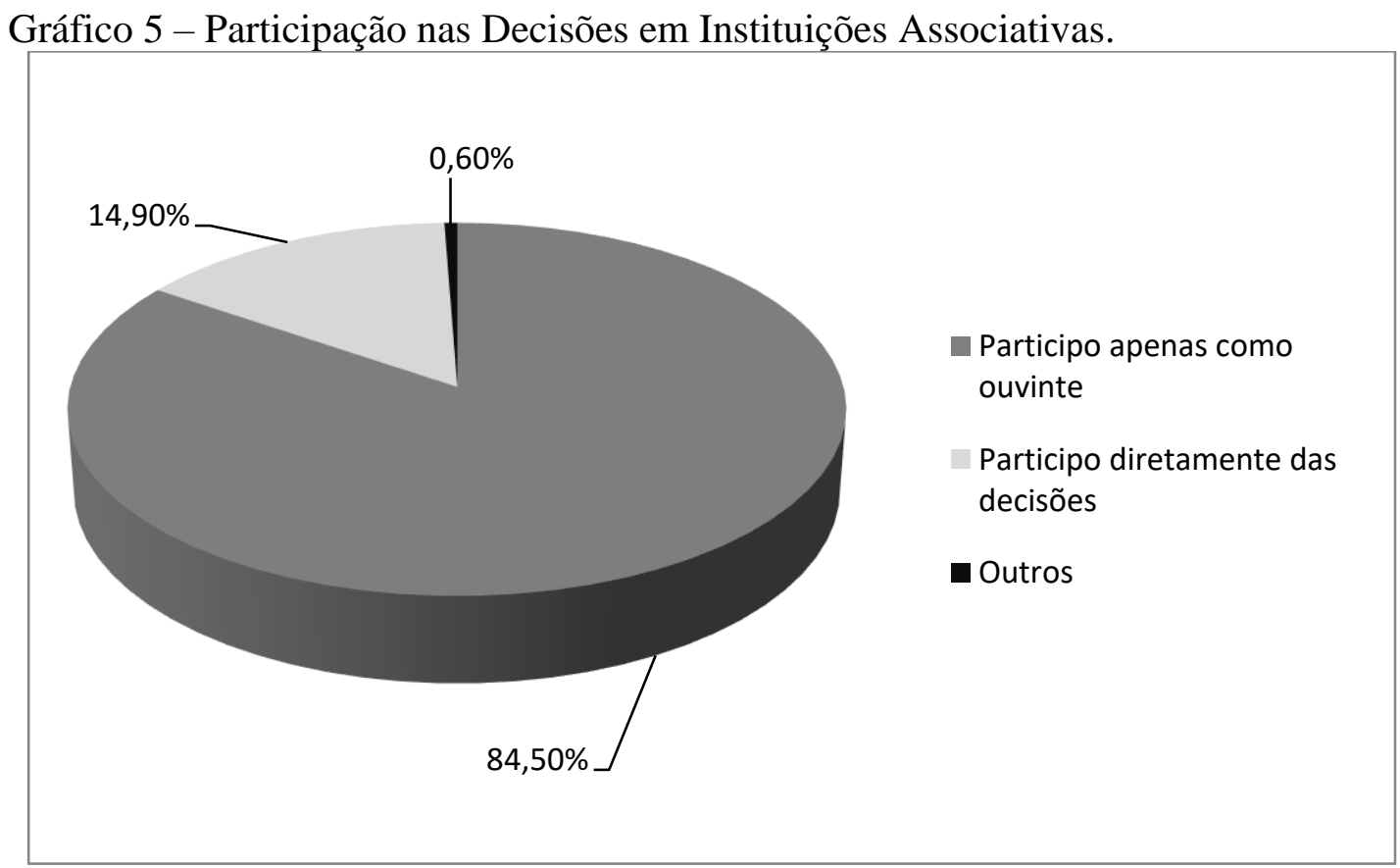

Fonte: Censo Pescarte.

O desafio de ampliação da participação feminina nos espaços associativos esbarra em vários obstáculos. O primeiro, de base cultural, em que a estrutura social define os espaços de participação feminina, ou seja, o espaço privado (doméstico) como o espaço por excelência para as mulheres, e, aos homens, o espaço público, acarretando na masculinização dos espaços das instituições associativas. Segundo, pelos custos da participação feminina, visto seu duplo papel na divisão sexual do trabalho, ou seja, o peso do trabalho reprodutivo junto à família - geralmente não é pensado o melhor horário, local, espaço e material humano para ficar com as crianças e a locomoção. O reflexo desses obstáculos participativos pode ser visualizado nos dados a respeito da frequência feminina nas reuniões das instituições associativas, que revelam que $43,9 \%$ das respondentes participam de quase todas as reuniões, $27,9 \%$ não se envolvem em quase nenhuma reunião, $13 \%$ não vai a nenhuma reunião e apenas $15,2 \%$ colaboram em todas as reuniões.

Gráfico 6 - Frequência Feminina nas Reuniões das Instituições Associativas. 


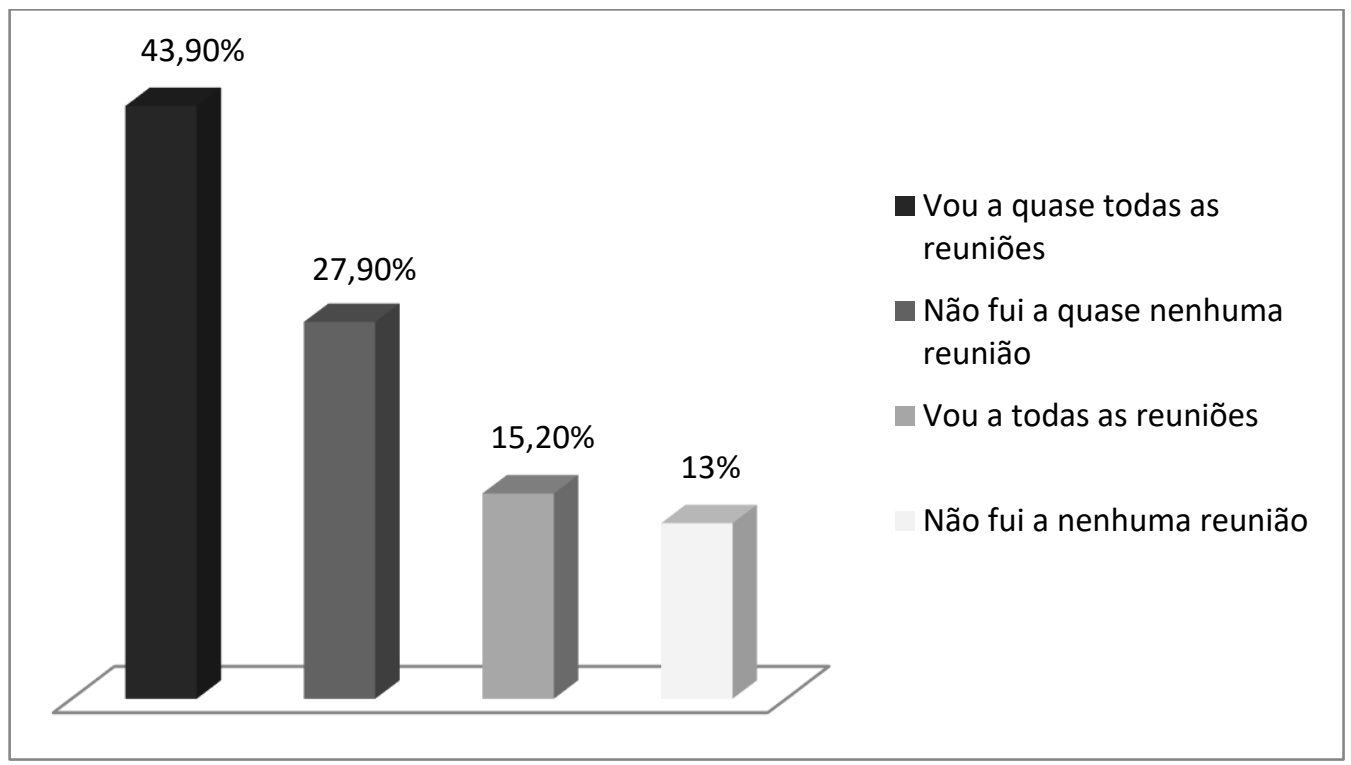

Fonte: Censo Pescarte.

Os dados indicam a necessidade de avanço na prática das instituições de representação de classe, de incorporação das pautas femininas e de mudança na estrutura ideológica que regula o funcionamento de tais instituições para melhor incorporar e fortalecer as pescadoras artesanais. O fato é que as pescadoras estão em constante luta em direção à sua emancipação, mas, para isso, é necessário vencer algumas trincheiras. Ao perguntarmos às pescadoras o que seria necessário para melhorar suas vidas na pesca, as mesmas destacaram a necessidade de mais investimentos em infraestrutura em seu local de trabalho $(18,7 \%)$; reconhecimento /valorização da atividade de pescadora / marisqueiras (12,7\%); investimento em creches e escolas (9,3\%); acesso a politicas públicas relacionadas à pesca (Programa Nacional de Fortalecimento da Agricultura Familiar-PRONAF, Seguro Defeso, Regularização da Documentação) $(5,4 \%)$ e melhoria na infraestrutura do local de trabalho/reconhecimento/valorização da atividade de pescadora / marisqueiras $(4,8 \%)$. Esse cenário demostra a importância de se fortalecer a pesca artesanal feminina; como elemento estratégico importante na solidificação da organização social dos pescadores em direção a movimentos mais emancipatórios da estrutura produtiva vigente na atualidade e na realidade da região em estudo. 


\section{4 - Considerações Finais:}

O princípio de que a categoria teórica gênero nos convida a ultrapassarmos as concepções encarceradoras que compreendem o sexo como uma "atitude natural", totalmente amolgada às construções sociais e às realidades biológicas e físicas. Dessa forma, ao restringirmos o debate ao ideário da imutabilidade do sexo, acabamos segregando os espaços socialmente definido para mulheres e homens, e reafirmamos os elementos definidores da diferença biológica e física. Em meio a esse contexto embrionário de definição teórica e de vivência, que o artigo priorizou a articulação analítica da categoria trabalho e relações sociais de gênero, como estratégia para contrapor os dualismos abstratos impetrados por concepções limitadoras, e em muitos casos, castradoras de processos emancipatórios importantes para os segmentos femininos na pesca artesanal.

De modo agregado, podemos delinear, com os dados coletados pelo Censo Pescarte, que as pescadoras estão em busca do fortalecimento de sua identidade profissional na cadeia produtiva da pesca. Dessa forma, as mesmas certificam-se que serão necessárias políticas públicas específicas, melhores segurança e condições de trabalho, que viabilizem sua dupla função produtiva e reprodutiva no núcleo familiar.

A necessidade de fortalecer as pautas femininas na pesca artesanal advém do fato de que essas trabalhadoras continuam concentradas em determinados nichos produtivos, desprotegidas, muitas vezes em condições de trabalho que originam problemas de saúde, o que torna, em longo prazo, penosa a vida dessas mulheres. Esses elementos segregacionistas precisam ser transpostos tanto no discurso ideológico, cultural, quanto na prática associativa de representação de classe como elemento de fortalecimento.

Portanto, o desafio do Projeto Pescarte concentra-se em assegurar uma participação mais ativa, que respeite as pautas de reivindicações e projetos emancipatórios das mulheres que sobrevivem da pesca artesanal na Bacia de Campos.

\section{THE FISH CLASS HAS TWO SEX: WORK AND GENDER RELATIONS IN THE PRODUCTION CHAIN OF CRAFTS IN THE CAMPOS / RJ.}

\section{ABSTRACT}


This article presents the research results developed by artisanal fisherfolk between 2015 and 2017, contiguous to fishing communities living in the Campos Basin, most vulnerable to the impacts of oil exploration in the North, Northwest and Lagos regions of the State of Rio de Janeiro. The objective is based on the need to understand the processes of incorporation of women in the fishing chain of production while denuding the social processes (in)visibilizadores in the field of sociability and social division of labor. We attempted to apply a survey of a census type of Survey and the data obtained were analyzed through SPSS, as a statistical tool to obtain the desired information.

Key words: work, gender relations and fishermen.

\section{LA CLASE PESQUERA TIENE DOS SEXOS: TRABAJO Y RELACIONES DE GÉNERO EN LA CADENA PRODUCTIVA DE LA PESCA ARTESANAL EN LA BACIA DE CAMPOS / RJ.}

\section{RESUMEN}

Este artículo presenta los resultados de investigación desarrollados junto a las pescadoras artesanales realizada entre 2015 y 2017 contiguos a las comunidades pesqueras residentes en la Cuenca de Campos más vulnerables a los impactos de la explotación del petróleo en las regiones Norte, Noroeste y Lagos del Estado de Río de Janeiro. El objetivo se sedimenta en la necesidad de comprender los procesos de incorporación de la mujer en la cadena productiva de la pesca al mismo tiempo que desnudamos los procesos sociales (in) visibilizadores en el campo de la sociabilidad y de la división social del trabajo. Se pretendió la aplicación de una investigación de naturaleza censal del tipo Survey y los datos obtenidos fueron analizados por medio del SPSS, como herramienta estadística para la obtención de la información deseada.

Palabras clave: trabajo, relaciones de género y pescadoras.

\section{5 - Referências Bibliográficas:}

ABRAMOVAY, M.; SILVA, R. da. "As Relações de Gênero na Confederação Nacional de Trabalhadores Rurais (CONTAG)”. In: ROCHA, M. I. B. da (Org). Trabalho e Gênero: mudanças, permanências e desafios. São Paulo: Ed. 34, 2000.

ARAÚJO, A. M. C.; FERREIRA, V. C. "Sindicalismo e Relações de Gênero no Contexto da Reestruturação Produtiva". In: ROCHA, M. I. B. da (Org). Trabalho e Gênero: mudanças, permanências e desafios. São Paulo: Ed. 34, 2000. p.309-346.

CHIES, P. V. "Identidade de Gênero e Identidade Profissional no Campo de Trabalho". Estudos Feministas, Florianópolis, 18(2), p.507-528, maio/agosto.2010. 
IAMAMOTO, M. V. Trabalho e Individuo Social: um estudo sobre a condição operária na agroindústria canavieira paulista. São Paulo: Cortez, 2011.

MARX, Karl; ENGELS, Friedrich. Prefácio à contribuição à crítica da economia política. In: Karl Marx e Friedrich Engels [1859]. São Paulo: Edições Sociais, 1977.

SCOTT, J. W. “O Enigma da Igualdade”. Estudos Feministas, Florianópolis, 13 (1): 216, p.11-30, janeiro/abril. 2005.

SILVA, C. A. da. Pesca Artesanal e Produção do Espaço: desafios para reflexão geográfica. Rio de Janeiro: Consequência, 2014.

SORJ, B. “Trabalho, gênero e família: quais políticas sociais?”. In: GODINHO, T.; SILVEIRA, M. L. da (Orgs). Politicas públicas e igualdade de gênero. São Paulo: Coordenadoria Especial da Mulher, 2004.

\footnotetext{
${ }^{1} \mathrm{~A}$ realização do Projeto Pescarte é uma medida de mitigação exigida pelo licenciamento ambiental federal, conduzido pelo IBAMA.

2 Definimos localidade como qualquer lugar em que se encontrem três ou mais famílias de pescadores artesanais que dependam, no todo ou em parte, da renda auferida pela pratica pesqueira.

${ }^{3}$ A unidade familiar é elemento central na análise dos continuísmos presentes nas relações sociais. Para Marx e Engels, a chave reguladora dos processos sociais está na concepção da propriedade, que tem sua forma embrionária na divisão do trabalho no seio familiar, visto que há uma distribuição desigual tanto no nível qualitativo / quantitativo (Marx \& Engels, 1977).

${ }^{4}$ São grupos de pescadores democraticamente eleitos pela comunidade pesqueira, sem remuneração prévia, para pensar, elaborar e propor projetos de geração de trabalho e renda via fortalecimento da organização social.
}

\section{Sobre os autores}

Valdir Júnio dos Santos é Sociólogo, Geografo e Professor do Programa de Pós-graduação em Planejamento Regional e Gestão de Cidades - Ucam. Endereço eletrônico: juniodossantos@yahoo.com.br 